\title{
Development of Simulation Model for the Propagation of Pressure Wave
}

\author{
Josef Soukup ${ }^{1}$, Milan Žmindák ${ }^{2}$, František Klimenda ${ }^{1}$ \\ ${ }^{1}$ Faculty of Mechanical Engineering, J. E. Purkyne University in Usti nad Labem, Pasteurova 3334/7, 400 96 Usti nad \\ Labem, Czech Republic, email: josef.soukup@ujep.cz, frantisek.klimenda@ujep.cz \\ ${ }^{2}$ Faculty of Mechanical Engineering, University of Žilina, Univerzitná 1, Žilina 010 26, Slovak Republic, E-mail: mi- \\ lan.zmindak@fstroj.uniza.sk
}

Detonation is a specific type of a rapid exothermic reaction, which always involves a detonation wave (in the explosive) and the shock wave (in the environment). Modelling of the pressure wave falls in the fluid flow and interference with obstacles in the flow. The purpose of this paper is to development of simulation model based on the finite element method (FEM) for shock wave propagation in air form the explosion of a spherical charge from TriNitroToluene (TNT) material. The air is the classical ideal gas and explosive material TNT is defined using Jones-Wilkins-Lee (JWL) equation. The computational model is 2D-dimensional model with four node axisymmetric elements. The effect of the explosion on the pressure distribution in the air and rigid surface (ground) is investigated. Numerical solution of the dynamic response was performed using commercial FEM software ADINA.

Keywords: Detonation, Shockwave, Impact

\section{Introduction}

Computer simulation technology has developed in close relation with both the computer industry and engineering processes. Therefore, engineering simulation plays a role in designing of machines, structures, piezoelectrical devices, medical devices, computers etc. [1]. The numerical treatment of complicated three-dimensional problems is becoming increasingly popular due to the fast development of computational hardware and the decline of computing costs. Today, there's practically no system or component that can't be improved via simulation. The simulation is not understood as a universal tool for analysis of the behaviour of the system that, but it is an effective alternative to the procedures of the experimental sciences. It is logical that the simulation makes the development of the new theories and design of new experiments for testing of these theories. The experiments are necessary for determination input data to simulation programs and for verification of numerical results and simulation models [2].

Numerical simulation are also very useful methods to describe wave propagation phenomena in more complex structures [3]. Extreme events are situations where the loading and/or response of a material, structure, or system exceeds that the normal conditions. In the field of extreme events research, physical experimentation is often limited according to the high rate, short time scales, large deformation response and or physical size that are inherently present in these problems. Explosion is a rapid physical and chemical change of state of mass by releasing of energy, pressure, heat, sound or light with consequential effects (labour, destruction, etc.).

Detonation is a specific type of rapid exothermic reaction, which is always accompanied by a detonation wave (in the explosive) and the shock wave (in the environment). This is a difference between other types of explosive transformation. Detonation can take place in different environments. Gas mixture, dispersion of solids in the air, aerosols, liquids and solids in various forms can detonate. It follows that detonation is not limited only to explosives (industrial or military), but it is possible in different systems if certain conditions are fulfilled.

The finite element method (FEM) is the most popular simulation method to predict the physical behaviour of systems and structures [4-7]. Much research work has been done in the field of numerical modelling during least years, which enables engineers today to perform simulations close to reality. Wave-propagation codes, also called hydrocodes, are typical class of numerical tool for the simulation of crash and impact and at the same time not linked to a specific kind of discretization. Typical representatives of hydrocodes are ABAQUS, ADINA, AUTODYNE，DYTRAN，LS-DYNA，PAM-SHOCK and RADIOS.

In the present study 2D computational model based on FEM for the wave propagation is developed. The simulation results are presented for the explosion TNT material in the air. The pressure in the vicinity of the explosion is evaluated and the pressure on the fixed wall is monitored as well.

\section{Detonation and explosion}

From an operational point of view, we can define an explosion as a release of energy into atmosphere in small enough volume and in a short time. In the second case, two waves (the pressure and the combustion one) are coupled and their velocity is supersonic compared to the unburned gas conditions in front the flame. This phenomenon is called detonation. We distinguish two types of explosion transformation: non-stationary detonation (explosion propagates with variable speed) and detonation (explosion propagates with constant velocity $D$ ). Between non-stationary detonation and detonation, exist a relationship $[8,9]$. We can define the initial velocity of initiation that detonator strike to explosive $D_{a}$. There are two cases: $D_{a}>D$ and $D_{a}<D$.

In the first case, non-stationary detonation will propagate from the boundary between explosive and detonator. Its speed will continuously decrease to a value $D_{a}$ that 
reaches in distance $L_{a}$. At all distances $L<L_{a}$ will be a stable detonation velocity $D$.

In the second case, detonation speed will increase from $D_{a}$ to $D$ in the distance $L_{a}$. For all distances $L>L_{a}$ the detonations speed will be stable and equal to $D$. It can be said that non-stationary detonations is always transformed to stationary.

The explosion over the plane surface of the body (e.g. on the ground) creates a wave image marked on the (Fig. 1) Firstly the shock wave spreads in all directions from the spherical charge, which impacts to the epicentre E on the surface of the body. At points outside of the epicentre wave impacts with angle $\alpha$, which increases with distance from the epicentre. Regular reflection occurs in the circle centred at the epicentre with radius $R_{E} \leq R_{E k r}$ and irregular reflection with radius $R_{E} \geq R_{E k r}$.

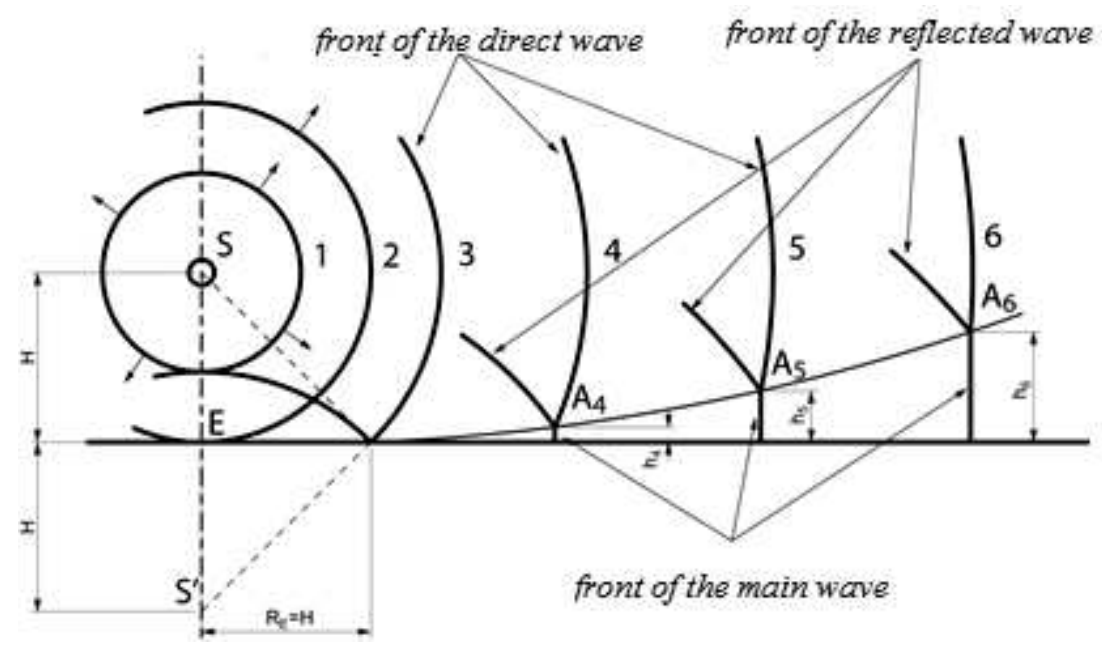

Fig. 1 Scheme of wave propagation in air explosion above the surface of the body

\section{Shockwave effect on the bodies}

When the body or structure is loaded with shock load, the shock wave first propagates and then reflected [10]. An interaction at a boundary produces a reflected wave, whereas an interaction at a boundary produces both reflected and transmitted waves. Shock waves effect on the structure has a different character depending on the type of the explosion, on the distance from blast, on the size of the charge and on the shape of the body. The theoretical solution derived from a single degree of freedom are proposed only for some selected problems [11]. Therefore,
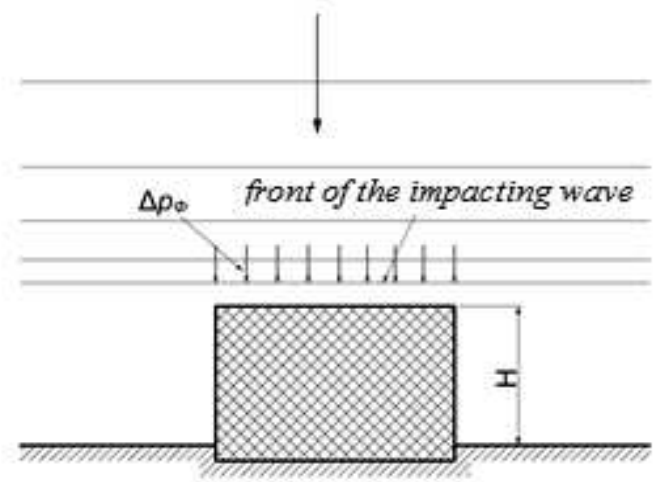

the results of the experimental research for the explosive loading scenarios are needed [12].

Structures are exposed to the incident waves in the closer zone of the explosion in air (Fig.2, left). The structure is firstly loaded from the top by overpressure reflection (Fig. 2, right). The structure is located in the layer of the compressed air after impacting of the shock wave on the ground and is loaded by overpressure from the reflected wave. It is assumed that the wave length greatly exceeds size of the obstacle.
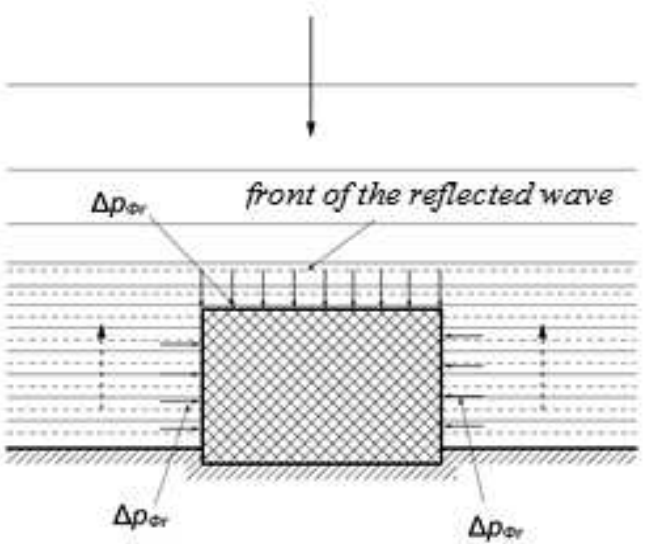

Fig. 2 Shockwave effect on overground structure, two stages of operation of the impact wave in the near area overground explosion

A different features has load of the overground structure exposed to the main wave (zone of the irregular reflection) or impact wave of the contact explosion. Firstly the wall reversed to the epicentre is loaded by overpressure of the reflected wave front propagates along the surface. Then the pressure is gradually applied to the side walls and upper horizontal wall and finally to the back side of the wall. In the moments after impact of the shock wave on the front wall, the pressure wave flows around and the overpressure drops rapidly as shows (Fig. 3). 

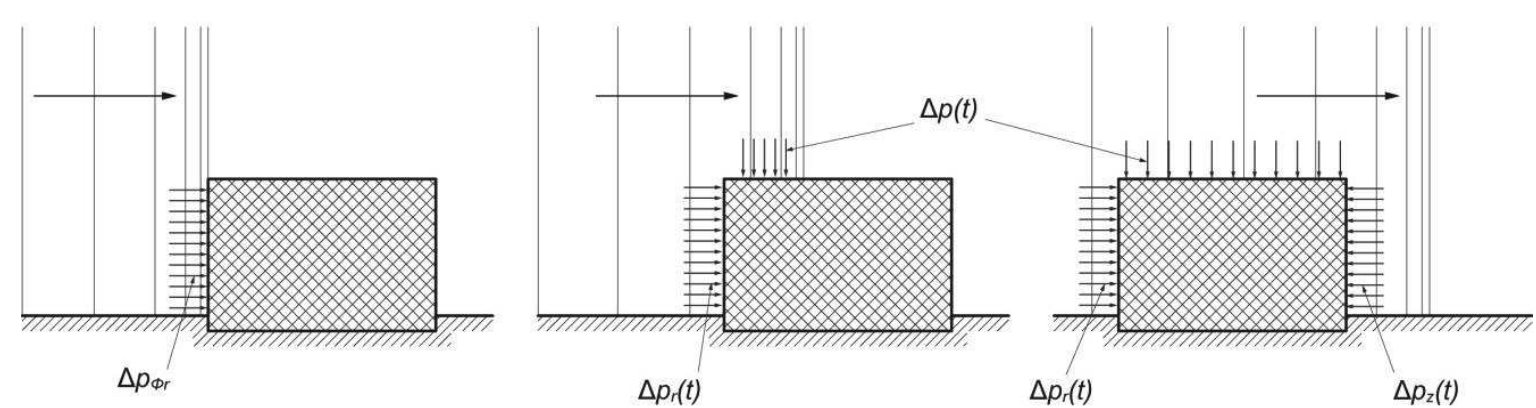

Fig. 3 Shockwave effect on overground structure, three stages of operation of the impact wave in the zone of irregular reflection or at a contact explosion.

\section{Background of theoretical model}

An explosion is an impulse load that is characterized by a high peak pressure and a short duration time (less than a second). Usually a Computational Fluids Dynamics (CFD) tool is used to simulate the explosion, including its movement in the $3 \mathrm{D}$ space, variation over time and peak pressure levels.

The mathematical model of any fundamental fluid dy-

$$
\mathrm{U}=\left(\begin{array}{c}
\rho \\
\rho \mathrm{u}_{\mathrm{x}} \\
\rho \mathrm{u}_{\mathrm{y}} \\
\rho \mathrm{u}_{\mathrm{z}} \\
\rho \mathrm{e}
\end{array}\right), \mathrm{E}=\left(\begin{array}{c}
\rho \mathrm{u}_{\mathrm{x}} \\
\rho \mathrm{u}_{\mathrm{x}}^{2}+\mathrm{p} \\
\rho \mathrm{u}_{\mathrm{x}} \mathrm{u}_{\mathrm{y}} \\
\rho \mathrm{u}_{\mathrm{x}} \mathrm{u}_{\mathrm{z}} \\
\rho \mathrm{h}_{0} \mathrm{u}_{\mathrm{x}}
\end{array}\right), \mathrm{F}=\left(\begin{array}{c}
\rho \mathrm{u}_{\mathrm{y}} \\
\rho \mathrm{u}_{\mathrm{y}} \mathrm{u}_{\mathrm{x}} \\
\rho \mathrm{u}_{\mathrm{y}}^{2}+\mathrm{p} \\
\rho \mathrm{u}_{\mathrm{y}} \mathrm{u}_{\mathrm{z}} \\
\rho \mathrm{h}_{0} \mathrm{u}_{\mathrm{y}}
\end{array}\right), \mathrm{G}=\left(\begin{array}{c}
\rho \mathrm{u}_{\mathrm{z}} \\
\rho \mathrm{u}_{\mathrm{z}} \mathrm{u}_{\mathrm{x}} \\
\rho \mathrm{u}_{\mathrm{z}} \mathrm{u}_{\mathrm{y}} \\
\rho \mathrm{u}_{\mathrm{z}}^{2}+\mathrm{p} \\
\rho \mathrm{h}_{0} \mathrm{u}_{\mathrm{z}}
\end{array}\right)
$$

Euler equation is often used to study compressible flow at high Mach numbers. Neglect of viscosity allows use of corser mesh grid the solid surfaces. The equations conserve mass, momentum and energy, and can be derived either an integral or a differential approach. The conservation of mass equation is

$$
\frac{\partial \rho}{\partial t}+\frac{\partial \rho u_{x}}{\partial x}+\frac{\partial \rho u_{y}}{\partial y}+\frac{\partial \rho u_{z}}{\partial z}=\mathbf{0}
$$

The energy equation in vector has form

$$
\frac{\partial T}{\partial t}+u \cdot \nabla T=\alpha \nabla^{2} T
$$

where $\rho$ is the density, $u_{x}, u_{y}, u_{z}$ are the velocity components, $T$ is the temperature, $\boldsymbol{\alpha}=\boldsymbol{k} / \boldsymbol{c}_{\boldsymbol{p}}$ is the thermal diffusity and $k$ is thermal conductivity and $c_{p}$ is the specific heat at constat pressure.

We note that in Euler's equations, instead the specific internal energy $e$ total enthalpy $h_{0}$ is used and the relationship between them is

$$
\rho e+p=\rho\left(c_{v} T+\frac{v^{2}}{2}+\frac{p}{\rho}\right)=\rho\left(c_{p} T+\frac{v^{2}}{2}\right)=\rho h_{0}
$$

$c_{\mathrm{v}}$ is the specific heat at constant volume, $\mathrm{v}$ is the resulting speed, The state gas equation for the pressure calculation is

$$
p=(k-1) \rho\left(e-\frac{c^{2}}{2}\right)
$$

For a numerical solution, the sets of differential equations and boundary conditions associates with fluid domains must be satisfied simultaneously. Basic boundary conditions in fluid mechanics are

- No-slip at the wall

$$
\left.v_{p}\right|_{\text {at the boundy }}=v_{w a l l}
$$

namics problem is governed by the Navier-Stokes equations [13].

For the high speed flows (e.g. flow over an aircraft), effects of viscosity are usually very small away from solid boundaries. For non-viscous flow, Navier-Stokes fluid flow equations simplify and they are Euler's fluid flow equation.

$$
\frac{\partial \mathrm{U}}{\partial t}+\frac{\partial(\mathrm{E})}{\partial x}+\frac{\partial(\mathrm{F})}{\partial y}+\frac{\partial(G)}{\partial z}=\mathbf{0}
$$

- Velocity continuity

$\boldsymbol{v}_{\boldsymbol{p}}$ (fluid 1) $\left.\right|_{\text {at the boundy }}=\boldsymbol{v}_{\boldsymbol{p}}$ (fluid 2) $\left.\right|_{\text {at the boundy }}$ (8) [14]

Other more complex boundary conditions are given in In modelling of various physical effects are used two basic formulation of the problem [15]:

- Lagrangian formulation.

- Eulerian formulation.

In the Lagrangian formulation, nodes of the finite element mesh are tightly connected with the geometry of the analysed body. Particles of the material are created by connecting of the nodes together. When the body is deformed, nodes move with material and elements are deformed (Fig. 4). The Lagrangian description allows an easy tracking of free surfaces and interfaces between different materials. It also facilitates the treatment of materials with history-dependent constitutive relations. Its weakness is its inability to follow large distortions of the computational domain without recourse to frequent remeshing operations.

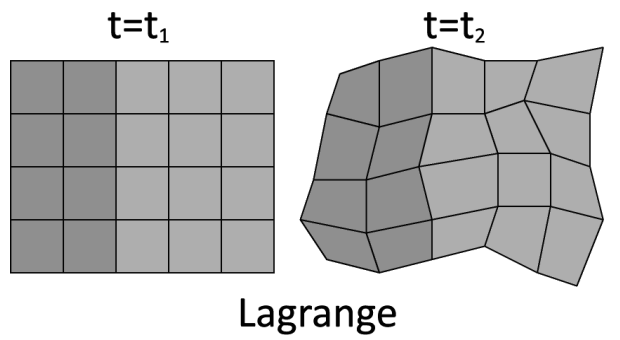

Fig. 4 Mesh deformation at the Lagrangian formulation 
The Eulerian formulation focuses attention on the stationary control volume and this volume is used to measure stability and continuity of the mass of fluid particles. The Eulerian formulation considers a separated equation for conservation of mass. This condition is contained in a determinant of the gradient deformation in Lagrangian formulation. This approach is applied in the study of fluid flow where the rate change of kinematic property is interest and not change of the shape body of fluid at a reference time. In the Eulerian description, large distortions in the continuum motion can be handled with relative ease, but generally at expense of precise interface definition and resolution of flow details. Fig. 5 shows a flow of mass through control volume.

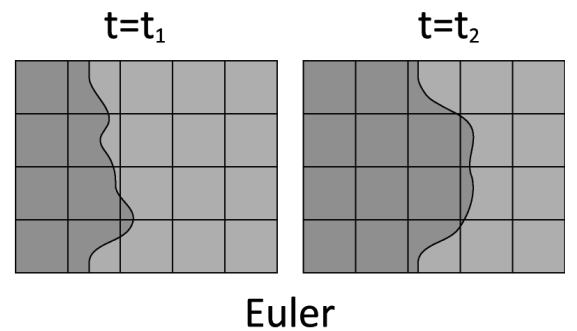

Fig. 5 Flow of mass by control volume

Modelling of the propagation pressure wave belongs to the field of fluid-structure interactions (FSI) with obstacles in flow domain. Therefore, it is appropriate to study the observed phenomena by software based on $\mathrm{Eu}-$ lerian formulation.

\section{Material models}

Hydrocodes computer software are able to predict unsteady, dynamic movement of the material by solving $\mathrm{Na}-$ vier-Stokes equations, conservation of mass and energy [16]. Also, the boundary conditions and initial conditions must be satisfied. Although boundary conditions are defined, additional relationships between variables (pres- sure, density, energy, temperature, etc.) must be specified. These relationships include state equation, equations defining model and model of failure of the material [17]. These must be defined for each material considered in computational model.

There were used two different material models in computational model:

\section{- Air}

Air can be adequately described using the state equation. In numerical models, it is assumed that the air is the classical ideal gas and its equation of state has form

$$
\boldsymbol{p}=(\boldsymbol{\gamma}-\mathbf{1}) \boldsymbol{\rho} \boldsymbol{e}
$$

where $p$-pressure, $\gamma$ - adiabatic index, $\gamma=c_{p} / c_{v}(\gamma=1.4$ for two-litter gas), $\rho$-density $\left(\rho=1.225 \mathrm{~kg} / \mathrm{m}^{3}\right), e-$ specific internal energy. The specific internal energy is function of temperature $T$

$$
e=\frac{R T}{\gamma-1}
$$

where $R=287.1 \mathrm{~J} \mathrm{~kg}^{-1} \mathrm{~K}^{-1}$ is the universal gas constant. For $T=288.15 \mathrm{~K}$ the specific internal energy is 206.82 J. $\mathrm{kg}^{-1}$.

\section{- TriNitroToluene (TNT)}

High-energy explosive material is defined using the Jones-Wilkins-Lee of state for explosives (JWL equation). The JWL equation is defined as follows

$$
p=A\left(1-\frac{\omega}{R_{1} V}\right) e^{-R_{1} V}+B\left(1-\frac{\omega}{R_{2} V}\right) e^{-R_{2} V}+\frac{\omega E}{V}
$$

where $A, R_{1}, B, R_{2}$ and $\omega$ are constants obtained by experiments and are published in the literature. Typical parameter for TNT are given in Table 1 . The ratio $V=\rho_{e} / \rho$ is defined using density of the explosive $\rho_{e}$ and $\rho$ is density of the detonation products and $E$ is the chemical energy of the explosive.

In hydrocodes, the explosion is modelled as an instantaneous process at which the explosive changes to gas. The volume change of the explosive material is completed at the beginning of the simulation.

Tab. 1 Parameters JWL of state equation

\begin{tabular}{|c|c|c|c|c|c|c|}
\hline$A[\mathrm{GPa}]$ & $B[\mathrm{GPa}]$ & $R_{1}[-]$ & $R_{2}[-]$ & $\omega[-]$ & $\begin{array}{c}\text { Velocity of detonation } \\
v_{d}[\mathrm{~m} / \mathrm{s}]\end{array}$ & $\begin{array}{c}\text { Chapman-Jouguet } \\
\text { Pressure }[\mathrm{GPa}]\end{array}$ \\
\hline 371.20 & 3.231 & 4.15 & 0.90 & 0.35 & 6930 & 21.0 \\
\hline
\end{tabular}

\section{Model of the pressure wave reflection}

The computational model is two-dimensional axisymmetric finite element model. Figure 6 shows the schematic computational model with the spherical charge explosion (TNT) with a mass of $1 \mathrm{~kg}$ at a distance of $400 \mathrm{~mm}$ from a perfectly rigid obstacle (ground). Volume dimensions in which the shock wave propagates are $1000 \times$ $1000 \mathrm{~mm}$.

Computational domain is divided into 250000 four node elements with dimensions of $2 \times 2 \mathrm{~mm}$. The element size is shown in the upper left corner of the Fig. 6. Fig. 7 shows wave image, which is caused by the explosion of charge. Detonation occurred at the time $t=0 \mathrm{~ms}$. The front of the direct wave reaches the obstacle about the time of $0.11 \mathrm{~ms}$ and begins to create a reflected wave. At $0.19 \mathrm{~ms}$, the intersection of the face reflected wave and the face of the direct (falling) wave begins to move away from the surface of the obstacle to form the main Mach's wave that propagates as a main shock wave. 


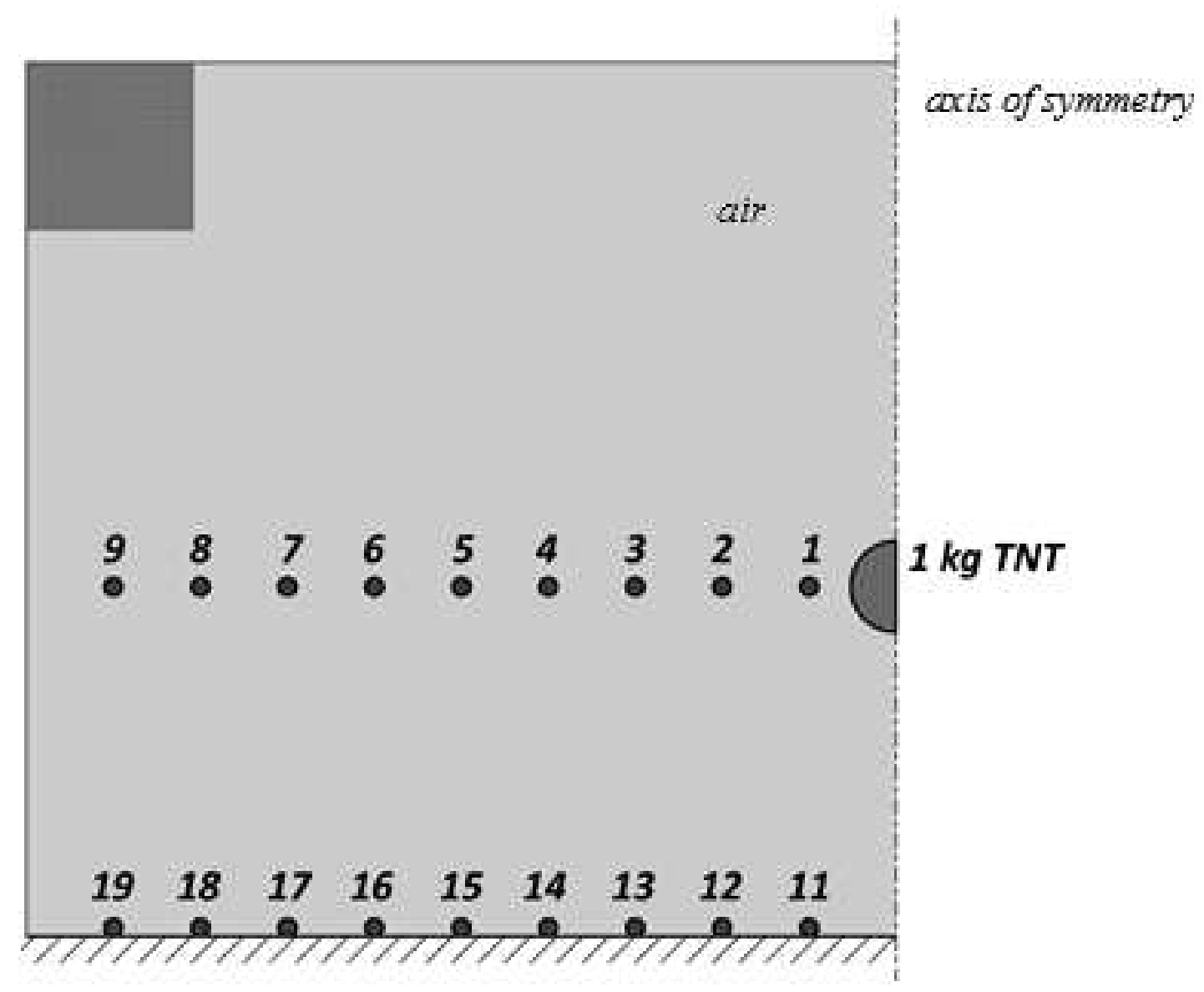

Fig. 6 Schematic computational model of the explosion of $1 \mathrm{~kg}$ TNT above the rigid surface

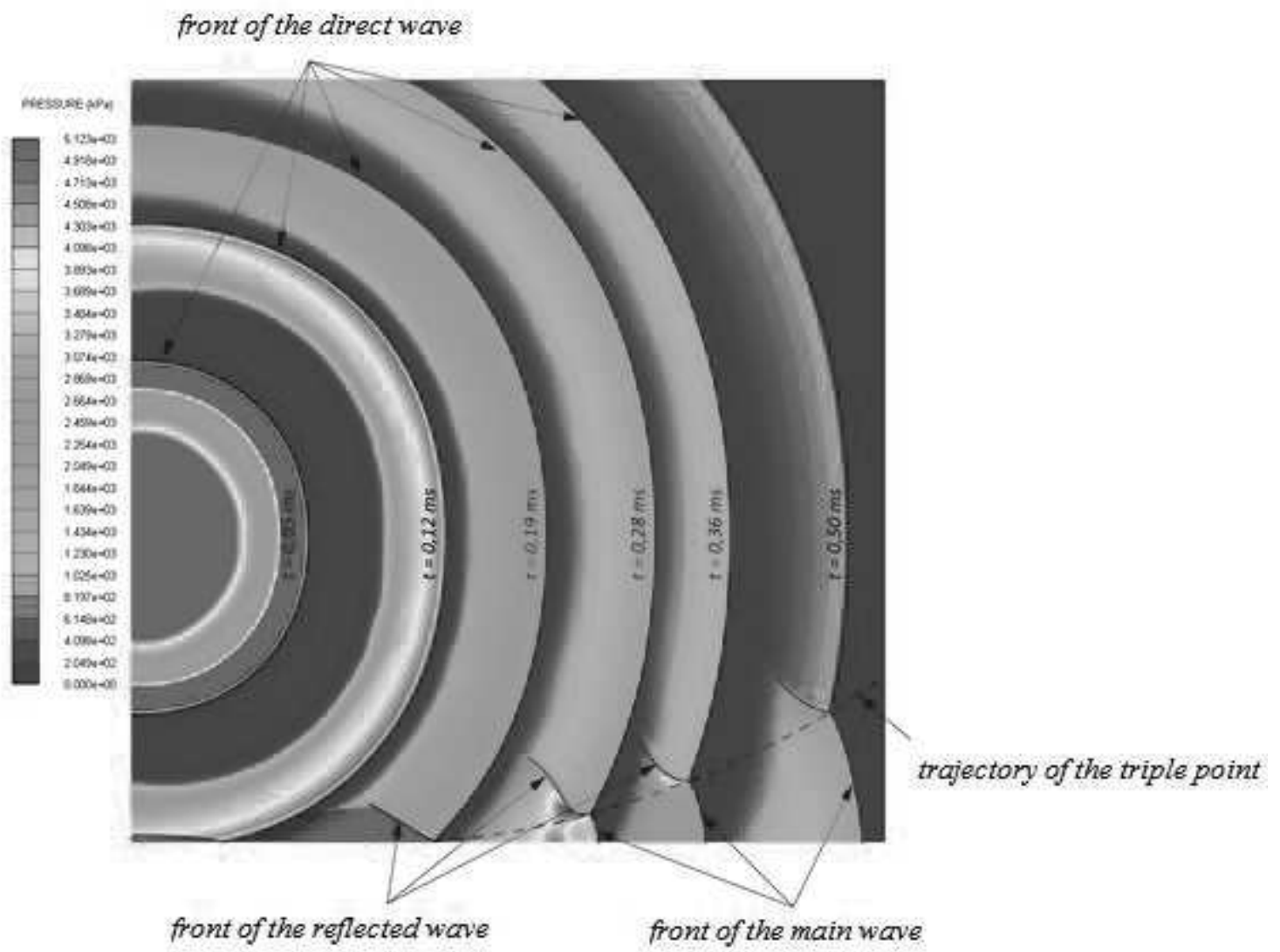

Fig. 7 Wave image created by numerical solution 
On Fig. 8 are shown pressure distributions in different places in the computational model. Points 1-9 are at distance of $400 \mathrm{~mm}$ from the surface and their spacing is $100 \mathrm{~mm}$. Points 11-19 are just above the rigid surface at distances of $100 \mathrm{~mm}$. When a direct shock wave propagates through space, the pressure falls on her front. In point 1 is maximum pressure $28.39 \mathrm{MPa}$ (at $t=$ $0.0219 \mathrm{~ms}$ ), in point 9 is maximum pressure only $1.11 \mathrm{MPa}$ (at $t=0.4589 \mathrm{~ms}$ ). Due to the superposition of the pressure of the direct and reflected wave is the pressure at the front of the main wave greater than at the front of the direct wave - in the point 19 is maximum pressure of $1.99 \mathrm{MPa}$.
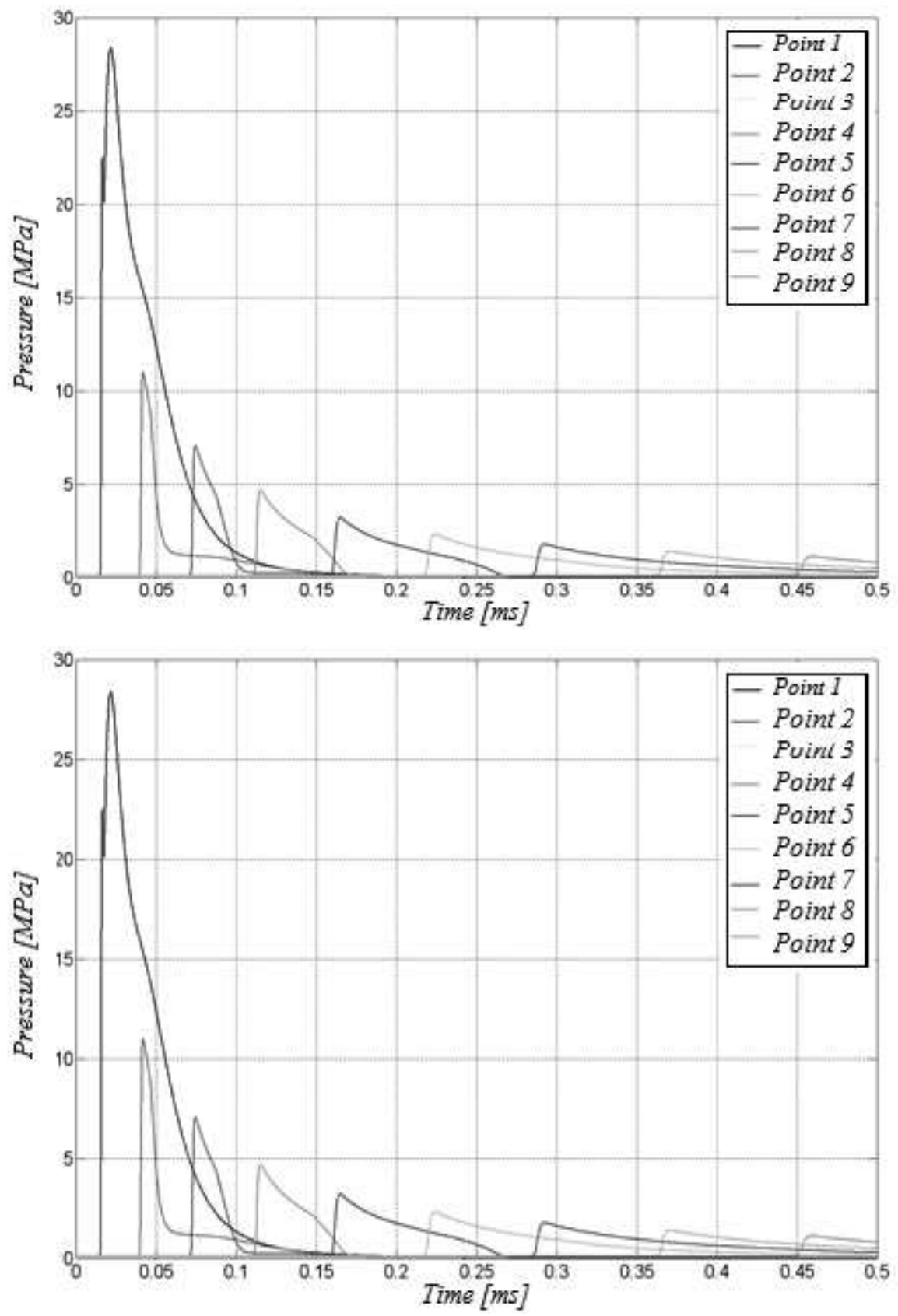

Fig. 8 Pressure distributions in different places of the model

\section{Conclusion}

The current software allows simulating the behaviour of the technical objects for the propagation of pressure wave from explosion. It is possible to simulate the changed boundary and initial conditions and their effect on the object without the need to do expensive and time consuming experimental tests. Comparing Fig. 1 and Fig. 7 was found that course of the waves obtained using numerical calculations is practically identical with the course assumed in theory. Based on the realized simulations it can be concluded that the computational simulation is a powerful tool for design blast loaded structures.

\section{Acknowledgement}

This work was supported by internal grant of Jan Evangelista Purkyně, Faculty of Mechanical Egineering (UJEP-IGS-2018-48-002-1). 


\section{References}

[1] WOLFE, CH. (2015). The future of simulation. ANSYS Advantage. Special issue: Oil and Gas, ANSYS, Inc., pp. 5-9.

[2] RAVIVI-CHANDAR, K. (2006). Murray Lecture: Role of experiments in mechanics. Experimental Mechanics., 46, pp. 5-18.

[3] GOPALAKRISHNAN, S. (2017), Wave propagation in Materials and Structures. CRC Press.

[4] CVAL, Z., SEDLACEK, F., KEMKA, V., (2017). Usage of FEM Simulations in Design of Piping Systems Manufacturing technology, Vol. 17, No. 4, pp. 469-473.

[5] DIŽO, J., HARUŠINEC, J., BLATNICKÝ, M. (2018). Computation of Modal Properties of Two Types of Freight Wagon Bogie Frames Using the Finite Element Method. Manufacturing Technology, April 2018, Vol. 18, No. 2, pp. 208-214.

[6] MIČIAN, M., PATEK, M., SLADEK, A. (2014). Concept of Repairing Branch Pipes on High-Pressure Pipelines by Using Split Sleeve, Manufacturing Technology, Vol. 14, No. 1, pp. 60-66.

[7] TVAROŽEK, J., KACKO, P., VALAŠIKOVÁ, $M$ (2010). Reconstruction of armoured bridge layer MT-72. Advances in Military Technology 5(2), pp. 121-136

[8] ABOUSEIF, G., TOONG, T.Y. (1982). Theory on unstable one-dimensional detonations. J. Combustion Flame, vol. 45, pp. 67-94.

[9] ABOUSEIF, G., TOONG, T.Y. (1986). Theory on unstable two-dimensional detonations: Genesis of the transverse waves. J. Combustion Flame, 63, pp. 191-207.

[10] ŽMINDÁK, M., PELAGIĆ, Z., BVOC, M. (2014). Analysis of high velocity impact on composite structures. Applied Mechanics and Materials, Vol. 617, pp. 104-109.

[11] AL-THAIRY, H. (2017). Single Degree of Freedom analysis method for steee beams under blast pressure using nonlineart resistance function with strain rate effects. Journal of Babylon University/Engineering Sciences, No.1, Vol. 25., pp. 298-313.

[12] FIGULI, L., BEDON, CH., ZVAKOVÁ, Z., JANGL, Š., KAVICKÝ, V. (2017). Dynamic Analysis of a blast loaded structure. Proceedia Engineering, 199, pp. 2463-2469

[13] MOLNÁR, V. (2006). Computational Fluid Dynamics. Application Basics CFD. STU Bratislava (in Slovak).

[14] ŽMINDÁK, M., GRAJCIAR, I. (1997). Simulation of the aquaplane problem. Computers and Structures, Vol. 64, No. 5/6, pp. 1155-1164.

[15] BAZILEVS, Y., TAKIYAVA, K., TEZDUYAR, T.E. (2013). Computational Fluid - Structure Interaction: methods and applications. Wiley.

[16] HIERMAIER, S. (2008), Structures Under Crash and Impact, Continuum mechanics, Discretization and Experimental Characterization. Springer.

[17] MCDOWELLA, D.L. et al. (2007). Plasticity-Related Microstructure-Property Relations for Materials Design, Key Engineering Materials Vols. 340-341, pp. 21-30. 